\title{
Treatment of distal ulcerative colitis with lidocaine
}

\author{
S BjörCK, MD, PHD, A DAHLSTRÖM, MD PhD, H AhLMAN, MD, PHD
}

SBJÖRCK, A DAHLSTRÖM, H AHLMAN. Treatment of distal ulcerative colitis with lidocaine. Can J Gastroenterol 1993;7(2):179-181. Treatment with lidocaine is gentle, with a high success rate and without observed side effects. Most of the refractory cases in this study responded to such treatment, even patients with severe chronic symptoms. Lidocaine seems to offer a good treatment. alternative to conventional treatment and in cases with refractory distal colitis.

Key Words: Lidocaine, Local anesthetics, Mucosal inflammation, Procto-sigmoiditis, Topical treatment, Ulcerative colitis

\section{Traitement de la colite ulcéreuse distale avec de la lidocaine}

RÉSUMÉ: Le traitement à la lidocaine agit doucement; il s'accompagne d'un taux cle réussite élevé, sans effets secondaires observés. Dans cette étude, la plupart des cas rebelles ont répondu à un tel traitement, même les sujets atteints de symptômes chroniques graves. La lidocaïne semble représenter une bonne solution de rechange par rapport au traitement classique et dans les cas de colite distale rebelle.

\section{D} STAL ULCERATIVE COLITIS IS confined to the rectum or rectosigmoid. The extension of disease can be assessed by rigid sigmoidoscopy and colonoscopy, and the estimated limits usually are based on macroscopic signs of inflammation.

The incidence of distal colitis has increased to between 40 and $70 \%$ in patients with ulcerative colitis (1). Patients with distal colitis are, in general, 10 years older at disease onset than patients with ulcerative colitis (aged 30 to 40 years). The treatment of distal colitis varies, but most patients

are treated topically with corticosteroid enemas and sulphasalazine perorally or topically with the new 5 -aminosalicylic acid compounds. Those patients with distal colitis who do not respond to treatment within six to eight weeks are referred to as having refractory distal colitis. The reason for this refractory state is unknown (2). In this paper the authors present a new approach to treat the mucosal inflammation in distal colitis with local anesthetics.

An imbalance of the autonomic nervous system in the pathophysiology of ulcerative colitis was suggested many

Department of Surgery, Lundby Hospital and Institute of Neurobiology, University of Göteborg, Göteborg, Sweden

Correspondence and reprints: Dr S Björck, Department of Surgery, Lundby Hospital and Institute of Neurobiology, University of Göteborg, Weiselgrensplatsen 2A, 41717 Gothenburg, Sweden years ago $(3,4)$. Such an imbalance with adrenergic preponderance might produce both increased epithelial turnover and increased vasomotor tone of the small vessels, resulting in mucosal damage. Several studies $(5-8)$ have reported morphological changes of the enteric nervous system in ulcerative colitis. The authors (9) confirmed hyperplasia of the mucosal adrenergic innervation in ulcerative colitis as previously reported by Kyösola et al (10). Studies of various gastrointestinal diseases over the past few years have pointed out altered distribution of enteric nerves and changed expression of transmitters within these nerves (1113). Several reports have recently focused on the interaction between enteric nerves and the immune system (neuroimmunomodulation) (14).

To date the authors have treated almost 200 patients with limited or extensive ulcerative colitis with a lidocaine gel. The initial hypothesis was that hyperactive local nervous reflexes were of pathogenetic importance in ulcerative proctitis. Blockade of enteric nerves by a local anesthetic seemed to reduce the inflammatory response. Topical application of a lidocaine gel resulted in good symptomatic relief and restored mucosal integrity in these patients $(9,15)$. Circumstantial evidence that local anesthesia has direct inhibitory effects on the inflammatory response and the proliferation of $\mathrm{T}$ cells also exists $(16,17)$. 


\section{PATIENTS AND METHODS}

Seventy-seven consecutive patients with histopathologically proven distal colitis were treated with topical lidocaine. Twenty-eight patients (eight males, 20 females, mean age SD: $33 \pm 13$ years) had proctitis; of these, 22 had chronic symptoms (refractory disease). Forty-nine patients had proctosigmoiditis (31 males, 18 females, mean age SD: $42 \pm 13$ years); of these, 32 had refractory disease.

Topical treatment: Enemas containing $400 \mathrm{mg}$ lidocaine hydrochloride was given twice a day as a gel preparation. Patients with proctitis (less than $15 \mathrm{~cm}$ above the dentate line) applied a $2 \%$ lidocaine gel (Astra, Södertälje, Sweden) intrarectally $20 \mathrm{~mL}$ twice a day; the others received $100 \mathrm{~mL}$ of gel twice a day $(400 \mathrm{mg}$ lidocaine in each dose). Patients on peroral sulphasalazine medication were allowed to continue such treatment with an unchanged dose. Patients on medication with cortisone enemas had this treatment withdrawn for a two-week period prior to onset of lidocaine therapy.

Clinical examination: Endoscopy with rectal biopsies was performed before the onset of treatment and at regular intervals every two to six weeks. The mucosal appearance and the mucosal vasculature, as well as the presence of contact bleedings, ulcers, mucus and pus, were described.

Histochemical procedures: The mucosal biopsies were studied immunocytochemically. Slides were incubated using the indirect method of Coons using fluorescein isothiocyanate-labelled secondary antisera. Adrenergic and peptidergic nerves were demonstrated using well-characterized antisera against tyrosine hydroxylase, neuropeptide $\mathrm{Y}$, vasoactive intestinal peptide, substance $P$, somatostatin and delta sleep-inducing peptide. An antiserum against the Schwann cell protein (S100) was also used to label nerve structures and polydendritic cells. The mucosal infiltration with $\mathrm{OKT} 4^{+}$and $\mathrm{OKT}^{+}$lymphocytes, and plasma cells was investigated using monoclonal antibodies (15).

Histological criteria for improvement of inflammation: Treatment with lidocaine was continued until two independent examiners could verify a clear reduction of subset of lymphocytes $\left(\mathrm{OKT}_{4}^{+}\right.$and $\mathrm{OKT}^{+}{ }^{+}$) and plasma cells in the lamina propria. This usually occurred in conjunction with a reduced number of polydendritic cells, and with restitution of epithelial height and mucus production. No obvious changes in the hyperinnervation pattern could be seen.

\section{RESULTS}

Clinical results: There were no complaints about side effects of treatment despite continuous therapy over several months in certain cases. Many patients reported an almost prompt relief of symptoms (within the first few days). No patient had fecal incontinence or experienced any problems in evacuating the rectum during treatment. In patients with proctitis, the discharge of blood and mucus gradually disappeared within the first seven to 10 days of treatment. In patients with tenesmus, symptoms were usually reduced or abolished within the first week of treatment.

Proctitis: All 28 patients with proctitis responded to treatment, with disappearance of symptoms and gradual improvement of mucosal histology. All patients went into remission, including the 22 patients refractory to other treatments. The proctitis patients were treated for $5.7 \pm 0.3$ weeks and were followed for $20.0 \pm 1.9$ months. During this observation, $68 \%$ of patients recurred (mucosal inflammation and symptoms).

Proctosigmoiditis: Clinical remission was achieved in 41 of 49 patients treated. Two patients did not respond to treatment; one developed fulminant total colitis and the other responded to subsequent cortisone therapy. In six patients, objective histological improvement was not achieved according to study criteria, but the patients still experienced symptomatic relief that made them continue with treatment. This patient group was treated for $3.5 \pm 0.3$ months. During the $15.6 \pm 1.1$ months of total observation, $42 \%$ of the patients recurred (mucosal inflammation).
Histological findings: The submucos and mucosal innervation varied in dividually between patients, probabl reflecting the severity of disease and th degree of inflammatory response. Earl in the disease process, hyperplasia adrenergic nerves and neuropeptide $Y$ immunoreactive nerves was obviou (enlarged varicose nerve terminals an thickened nerve bundles). The mo prominent finding in chronic case (refractory disease) was hyperplasia substance $\mathrm{P}$ and vasoactive intestin peptide-immunoreactive nerve fibre and terminals. These nerve terminal appeared to innervate the mucosa in patchy pattern. Usually the innervation pattern was not changed during treat ment. The total innervation pattern o the submucosa and mucosa was assesse from the distribution of S100-im munoreactive fibres. This antiserun also labels polydendritic antigen presenting cells; these cells were abundant in the diseased mucosa, usuall located subepithelially along crypts, but with healing and restitution of the epithelium during treatment, they disappeared from the mucosa.

$\mathrm{T}$ cells $\left(\mathrm{OKT}_{4}^{+}\right.$and $\mathrm{OKT}^{+}{ }^{+}$were found in a very low number in healthy controls, but invaded the lamina propria and epithelial lining massively during active disease. These subsets of lymphocytes were part of the inflam. matory response in cryptitis and crypt abscesses. During treatment with lidocaine the number of lymphocytes gradually disappeared, starting from the luminal side of the mucosa. The treatment was continued until the number of lymphocytes was markedly reduced and confined to vessels within the lamina propria. The number of plasma cells in the lamina propria was reduced almost in parallel with the lymphocytes.

\section{DISCUSSION}

A new approach to treat distal colitis, both in acute and chronic (refractory) phases, has been presented, ie, topical treatment of the inflamed mucosa with a local anesthetic. The rationale for this treatment was block hyperreactive nervous reflexi and inhibit transmitter release from hy. 
perplastic enteric nerves within the mucosa and submucosa. It cannot be concluded whether the changed innervation in ulcerative colitis is secondary to the mucosal inflammation or whether it is a pathogenetic step in the development of mucosal inflammation. Besides nervous blockade, lidocaine can influence immune functions, eg, lymphocyte proliferation and macrophage migration $(16,17)$. The beneficial effect of lidocaine observed in ulcerative colitis (symptoms, endoscopy and histology findings) may be a summation effect in which nerves, inflammatory cells and cell products (lymphokines) all are influenced by treatment in a therapeutic way. Most patients have experienced very rapid relief of symptoms, even patients with refractory disease. However, it must be emphasized that it is much easier to treat patients with the early acute phase compared with the chronic phase (characterized by distorted architecture and low resistant cuboidal epithelium).

The lower recurrence rate observed after treatment for proctosigmoiditis, compared with proctitis, may reflect

\section{REFERENCES}

. Farmer RG. Nonspecific ulcerative proctitis. Gastroenterol Clin North Am 1987;16:157-74.

2. Järnerot $\mathrm{G}$, Lennard-Jones J, Bianchi-Porro G, Brynskov ], Campieri M, Present D. Medical treatment of refractory distal ulcerative colitis. Gastroenterol Internat 1991;4:93-8.

Wolf S. The central nervous system regulation of the colon.

Gastroenterology 1966;51:810-24.

4. Berger RL, Lium R. Abdominal postganglionic sympathectomy: $\mathrm{A}$ method for the production of a ulcerative colitis-like state in dogs. Ann Surg 1960;152:266-73.

;. Storsteen KA, Kernohan JW, Bargen JA. Myenteric plexus in chronic ulcerative colitis. Surg Gynecol Obstet 1953;97:335-43.

. Okamoto E, Kakutani T, Iwasaki T, Namba M, Ueda T. Morphological studies of myenteric plexus of the colon in chronic ulcerative colitis. Med J Osaka Univ 1964;15:85-106. 7. Dvorak AM, Osage JE, Monahan RA, Dickersin GR. Crohn's disease: Transmission electron microscopic studies IIl: Target tissues. Proliferation the relative importance of long term therapy rather than differences between disease entities. In this series, patients with proctosigmoiditis had a longer duration of symptoms (four times longer) than patients with proctitis alone. Patients with proctitis had a relapse rate of $68 \%$ over an observation time of 20 months in accordance with earlier reports (18). The recurrence rate for patients with proctosigmoiditis was $40 \%$ over 16 months, which is a good result with respect to the high percentage of patients with refractory disease in this series.

Parameters reflecting the degree of inflammation were easy to follow, ie, T lymphocyte infiltration, and presence of polydendritic and plasma cells within the lamina propria and epithelium. The polydendritic cells are antigen-presenting cells (19). Since these cells are localized subepithelially in the mucosa during active disease, this may indicate that the epithelium has a decreased resistance, with leakage of antigens into the lamina propria. One important function of plasma cells is to produce secretory immunoglobulin A

of an injury to smooth muscle and the autonomic nervous system. Human Pathol 1980;11:620-34.

8. Koch TR, Carney JA, Go VLW. In: MacDermott J, ed. Inflammatory Bowel Disease: Current Status and Future Approach. Amsterdam: Elsevier Science Publishers, 1988:25-30.

9. Björck S, Dahlström A, Ahlman, H. Topical treatment of ulcerative proctitis with lidocaine. Scand J Gastroenterol 1989;24:1061-72.

10. Kyösola K, Penttilä O, Salaspuro M. Rectal mucosal adrenergic innervation and enterochromaffin cells in ulcerative colitis and irritable colon. Scand J Gastroenterol 1977;12:363-7.

11. Burnstock G. Changes in expression of autonomic nerves in ageing and disease. J Auton Nerv Syst 1990;30:525-34.

12. Belai A, Lincoln J, Milner P, Burnstock G. Differential effect of streptozotocin-induced diabetes on the innervation of the ileum and distal colon. Gastroenterology 1991;100:1024-32.

13. Hendry J, Hill C,eds. The Autonomic Nervous System: Development, Regeneration and Plasticity of the Autonomic Nervous System. London: to cover and protect the luminal surface of the intestine from pathogens, and this function seems to be enhanced in the damaged mucosa (19). These cell types all decreased during treatment with lidocaine. The general morphological features of the diseased mucosa (ie, a low and disrupted epithelium, reduced mucous contents of goblet cells, and shortening and branching of crypts) were also restituted to a high degree during treatment.

\section{CONCLUSIONS}

Treatment with lidocaine is gentle, with a high success rate and without observed side effects. Most of the refractory cases in this study responded to such treatment, even patients with severe chronic symptoms. Lidocaine seems to offer a good treatment alternative to conventional treatment and in cases with refractory distal colitis.

ACKNOWLEDGEMENTS: This work was supported by grants from the Swedish MRC $(2207,5520)$, the Assar Gabrielsson Foundation and the Ulf Widengren Foundation.

Harwood Academic Publishers. (In press)

14. MacDermott JR, Elson O. Mucosal immunology. Gastroenterol Clin North Am 1991;3:2.

15. Björck S, Dahlström A, Johansson L, Ahlman H. Treatment of the mucosa with local anesthetics in ulcerative colitis. Agents Actions, Special Conference Issue 1992:C60-72.

16. Ramus GV, Cesano L, Barbalonga, A. Different concentrations of local anesthetics have different modes of action on human lymphocytes. Agents Actions 1983;13:333-41.

17. Dickstein R, Kiremidjian-Schumacher L, Stolzky G. Effects of lidocaine on the function of immunocompetent cells. I. In vitro exposure of mouse spleen lymphocytes and peritoneal macrophages. Immunopharmacol 1985;9:117-25.

18. Myers A, Humphrys DM, Cox EV. A ten-year follow-up of hemorrhagic proctitis. Postgrad Med J 1976;52:224.

19. Mayer, L. Antigen presentation in the gut. In: Targan SC, Stanahan F, eds. Immunology and Immunopathology of the Liver and Gastrointestinal Tract. New York: Igaku-Shoin Medical Publishing, Inc 1990:33-48. 


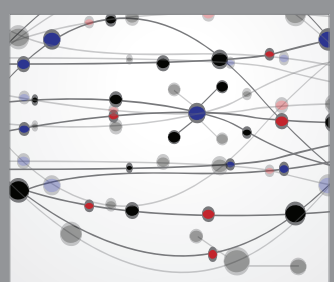

The Scientific World Journal
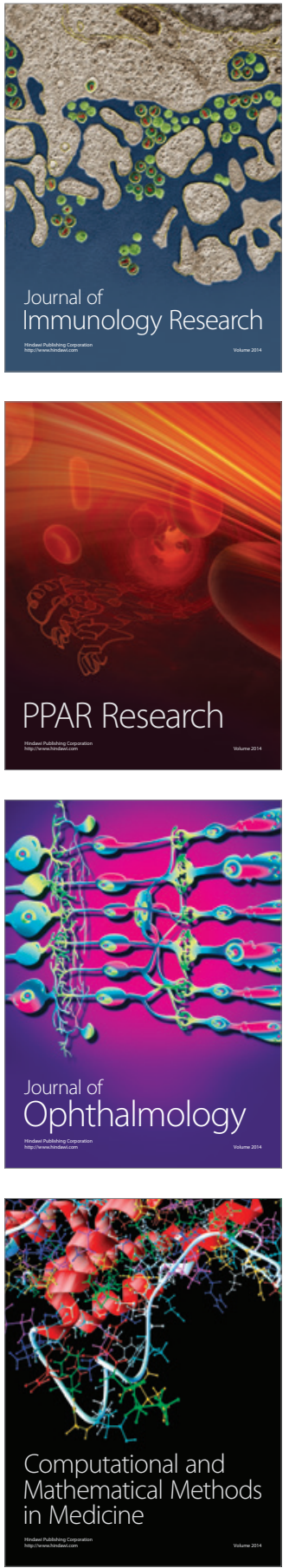

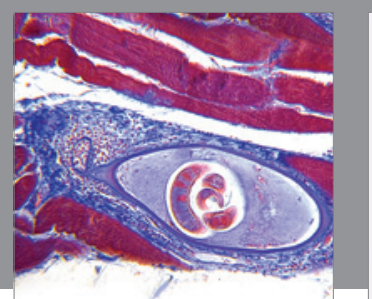

Gastroenterology Research and Practice

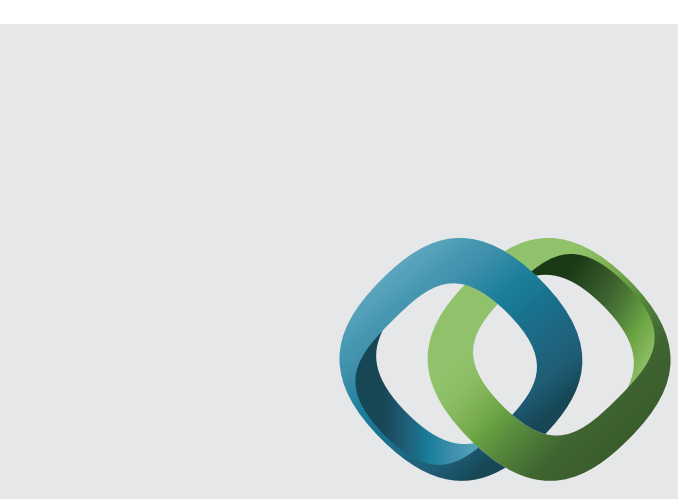

\section{Hindawi}

Submit your manuscripts at

http://www.hindawi.com
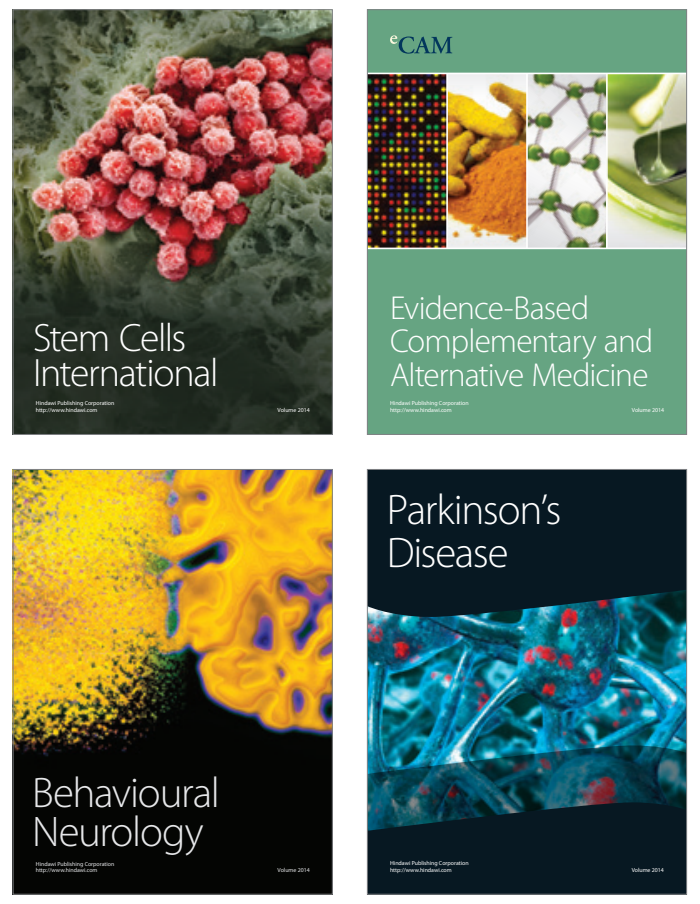
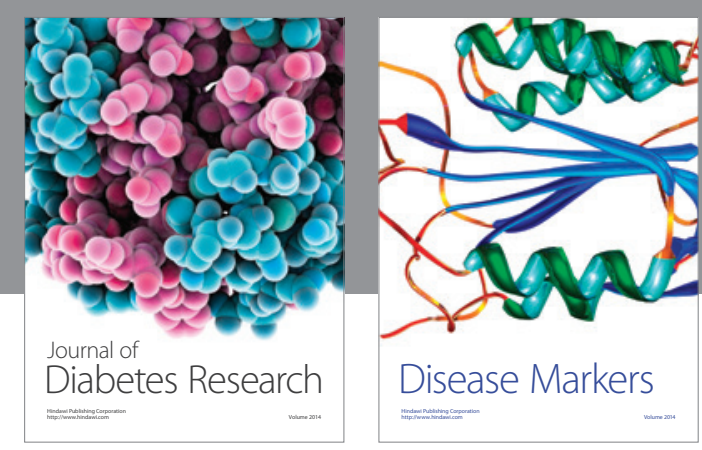

Disease Markers
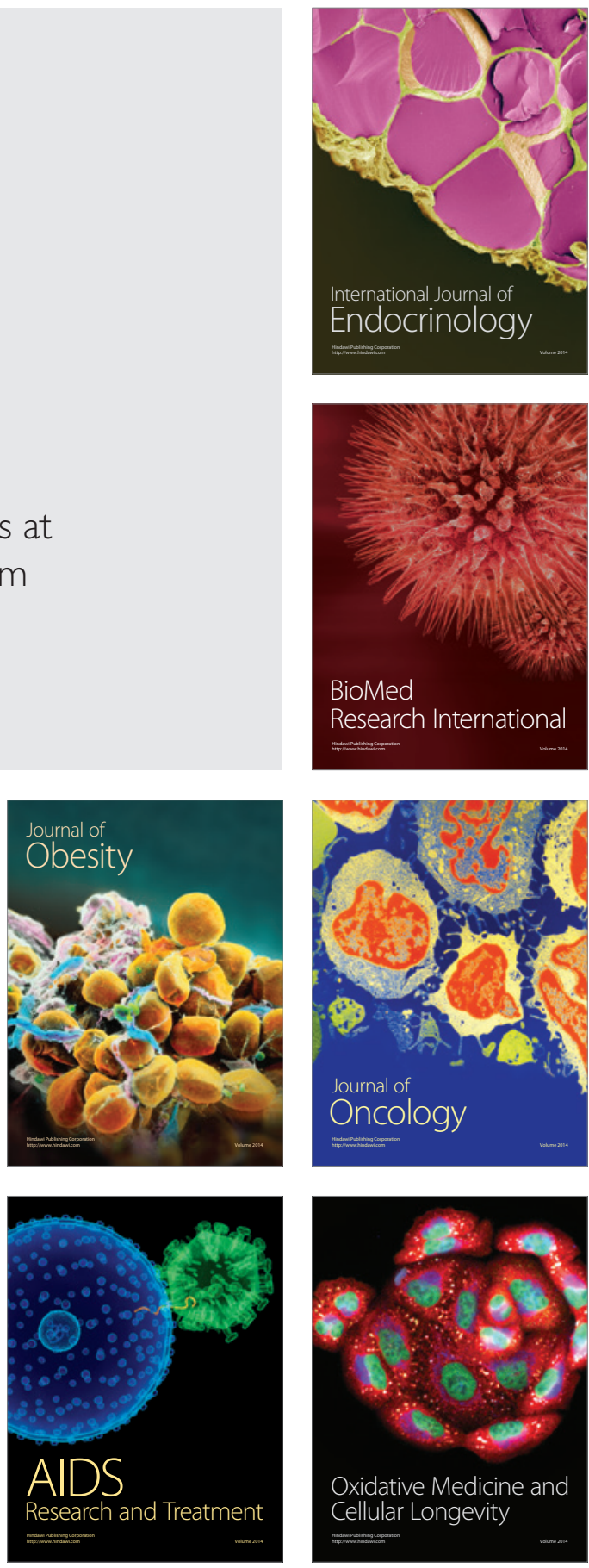